\title{
SIMULAÇÃO PELO MODELO CENTURY DA DINÂMICA DA MATÉ RIA ORGÂNICA DE UM ARGISSOLO SOB ADUBAÇÃO MINERAL E ORGÂNICA ${ }^{(1)}$
}

\author{
L. F. C. LEITE ${ }^{(2)}$, E. S. MENDONÇA(3) \& P. L. O. A. MACHADO(4)
}

\begin{abstract}
RESUMO
Os modelos de simulação são ferramentas essenciais para o entendimento da dinâmica da matéria orgânica do solo e da transformação de seus comparti mentos em solos tropicais. Os objetivos deste estudo foram: (a) si mular por meio do modelo Century os efeitos de sistemas de produção de milho sob adubação orgânica e mineral sobre a dinâmica da matéria orgânica em um Argissolo Vermelho-Amarelo, e (b) comparar os estoques de C orgânico total (COT), $\mathrm{N}$ total (NT) e dos compartimentos de $\mathrm{C}$ medidos por meio de métodos de laboratório e estimados pelo modelo Century na camada superficial $(0-20 \mathrm{~cm})$. A área em estudo, sob Floresta Atlântica (FA) até o ano de 1930, foi cultivada com milho e feijão por aproximadamente 50 anos, até à instalação do experimento no ano de 1984. Os tratamentos constaram de combinações entre três doses de adubo mineral, correspondentes a de 0,250 e $500 \mathrm{~kg} \mathrm{ha}^{-1}$ da fórmula 4-14-8, e duas doses de adubo orgânico (esterco bovino com palha de soja e feijão), nas doses de 0 e $40 \mathrm{~m}^{3} \mathrm{ha}^{-1}$. Os métodos de laboratório incluíram determinações do COT, do NT, do C da biomassa microbiana $\left(C_{\text {MIC }}\right)$, representando o compartimento ativo, e do $C$ da fração leve $\left(C_{F L}\right)$, referenciando o compartimento lento. $O$ compartimento passivo foi obtido por diferença. A parametrização do modelo Century foi realizada a partir dos dados obtidos no experimento e na literatura, enquanto as simulações da dinâmica do COT, NT e dos compartimentos ativo de C lento e passivo incluíram as mudanças no uso da terra ocorridas de 1930 a 2050. O modelo Century estimou diminuição nos estoques de COT, NT e dos compartimentos de $\mathrm{C}$ desde a derrubada da FA até o início do experimento e apenas nos tratamentos com adubação orgânica foi observada recuperação desses estoques. $\mathrm{O} \mathrm{Cm}_{\mathrm{IC}}$ e $\mathrm{O} \mathrm{C}_{\mathrm{FL}}$ foram mais sensíveis às mudanças no manejo do que $\mathrm{o}$
\end{abstract}

(1) Parte da pesquisa realizada para a Tese de Doutorado do primeiro autor, apresentada ao Departamento de Sol os da U niversidade Federal de Viçosa - UFV. Recebido para publicação outubro de 2002 em e aprovado em dezembro de 2003.

(2) Pesquisador da Embrapa - Centro de Pesquisa Agropecuária do Meio Norte - CPAM N. Caixa Postal 1, CEP 64006-220 Teresina (PI). E-mail: luizf@cpamn.embrapa.br

(3) Professor do Departamento de Solos, Universidade Federal de Viçosa - UFV. CEP 36570-000 Viçosa (MG). Bolsista do CNPq. E-mail: esm@ufv.br

(4) Pesquisador da Embrapa Solos. Rua J ardim Botânico 1024, CEP 22460-000 Rio de J aneiro (RJ ). E-mail: pedro@cnps.embrapa.br 
COT, o que indica a importância desses comparti mentos no estudo da di nâmica da matéria orgânica, especialmente em solos tropicais. Os estoques de COT, NT e dos compartimentos de C (lento e passivo), simulados pelo modelo Century, foram similares aos estoques medidos. Os estoques de COT (em Mg ha-1 $\mathrm{de}^{\mathrm{C}}$ ), medidos e si mulados pelo modelo Century, foram bem correlacionados $\left(R^{2}=0,93\right.$; $p<0,01)$, assim como para o $C$ do compartimento ativo $\left(R^{2}=0,84 ; p<0,05\right)$, lento $\left(R^{2}=0,87 ; p<0,05\right)$ e passivo $\left(R^{2}=0,91 ; p<0,05\right)$. Também para os estoques de NT (em Mg ha-1 de N), medidos e simulados pelo modelo Century, houve alta correlação $\left(R^{2}=0,93 ; p<0,01\right)$. O modelo Century demonstrou bom desempenho para simular a dinâmica da matéria orgânica em solos tropicais ácidos.

Termos de indexação: compartimentos de carbono, carbono orgânico do solo, solos tropicais.

\title{
SUMMARY: SIMULATION OF ORGANIC MATTER DYNAMICS IN AN ARGISOL UNDER MINERAL AND ORGANIC FERTILIZATION WITH THE CENTURY MODEL
}

\begin{abstract}
Simulation models are essential instruments to understand soil organic matter dynamics and theturnover of its pool s in tropical soils. The objectives of this study were: (a) simulatetheeffects of maize production systems under organic and mineral fertilization on soil organic matter dynamics of an Ultisol using the Century mode; (b) to compare total carbon (TOC) and total nitrogen stocks (TN) and the carbon pools (C) measured in the laboratory and estimated by the Century model for the surface soil layer $(0-20 \mathrm{~cm})$. The study area had been part of the Atlantic F orest (FA) until 1930. After that it had been used for maizel bean production up to 1984, when thefield experiment was set up. Thetreatments included a combination of threelevel s of mineral fertilizer at doses of 0,250 and $500 \mathrm{~kg} \mathrm{ha}^{-1}$ of the 4-14-8 formula and two levels of organic fertilizer (animal manure with soybean and bean straw) at doses of 0 and $40 \mathrm{~m}^{3} \mathrm{ha}^{-1}$. Laboratory determinations included TOC and $\mathrm{TN}$, microbial biomass $\mathrm{C}$ representing the active $\mathrm{C}$ pool and carbon of the light fraction representing thesl ow $C$ pool. ThepassiveC pool was determined by difference TheCentury model was parameterized with data from thepresent experiment and from literature, whereas thesimulations of thedynamics of TOC, TN and theactive, slow, and passivepool included land usechanges between 1930 and 2050. TheCentury model esti mated a decrease in TOC, TN and the different carbon pools between the slash and burn of the Atlantic Forest until the establishment of the field experiment. Only in the treatments with organic fertilization it was observed a recovery of thesepools. Biomass carbon and thecarbon of thelight fraction were moresensitiveto changes in management than TOC. This highlights therel evance of these pools in studies of organic matter dynamics, particularly in tropical soils. Measured and simulated values of TOC (in Mg ha-1 of C) were well correlated $\left(R^{2}=0.93 ; p<0.01\right.$ ). This was al so observed for theactive $\left(R^{2}=0.84 ; p<0.05\right)$, thesl ow $\left(R^{2}=0.87 ; p<0.05\right)$ and the passive $\left(R^{2}=0.91 ; p<0.05\right) C$ pools. Both measured and simulated values of $T N$ (in $\mathrm{Mg} \mathrm{ha}^{-1}$ of $\mathrm{N}$ ) were well correlated $\left(\mathrm{R}^{2}=0.93 ; \mathrm{p}<0.01\right)$. The Century model showed a good performance to simulatesoil organic matter dynamics in tropical soils.
\end{abstract}

Index terms: Century model, carbon pools, soil organic carbon, tropical soils.

\section{INTRODUÇÃO}

Os processos de transformação do C e N no solo influem diretamente na qualidade do solo. Nos últimos anos, o C orgânico do solo vem sendo sistematicamente quantificado tanto na forma de teores totais quanto em diferentes compartimentos no solo. I sto se dá pela alta relevância que o solo tem, por meio do seu manejo, de evitar que o C seja transferido para a atmosfera ou que permaneça retido no material do solo, contribuindo para a mitigação das mudanças climáticas (Watson et al., 2000). Com a evolução dos métodos experimentais de longo prazo e o desenvol vimento dos model os de simulação, a pesquisa foi acumulando informações importantes acerca da dinâmica do C no solo e, assim, melhorando o manejo da matéria orgânica do solo (Shaffer et al., 2001). 
Diversas técnicas de fracionamento físico e quími co têm si do desenvolvidas para separar eisolar frações de C orgânico total do solo (COT) (Cheng \& Kimble, 2001). Em geral, os compartimentos físicos de $C$ são diferenciados pelo tamanho e incluem resíduos facilmente reconhecidos (tamanho $>2 \mathrm{~mm}$ ): fração leve (tamanho de 0,25 a $2 \mathrm{~mm}$ ), que pode ser separada por flotação em solução de alta densidade (ex. $1,8 \mathrm{~g} \mathrm{~cm}^{-3}$ ), e fração pesada (densidade $>1,8 \mathrm{~g} \mathrm{~cm}^{-3}$ ), que pode ser separada após dispersão e sedimentação. Os compartimentos quími cos de C, após extração das partículas minerais do solo (ex. utilizando-se solução de $\mathrm{NaOH}$ ), são obtidos com base na solubilidade de componentes do COT, ou seja, as substâncias húmicas, em di ferentes sol uções básicas eáci das. Os componentes incluem os ácidos fúlvicos, ácidos húmicos e as huminas (Ping et al., 2001).

O C da biomassa microbiana pode ser obtido por meio dos métodos fumigação-extração (J enkinson \& Polwson, 1976) ou irradiação-extração (I slam \& Weil, 1998). No entanto, verifica-se que esses métodos físicos ou químicos usados para estimar compartimentos de C com taxas de decomposição definidas não são precisos, pois a labilidade biológica não depende somente das formas físicas e químicas do C (Duxbury et al., 1989), mas também da interação dos compostos de C com outros constituintes do solo e condições ambientais (Motavalli et al., 1994).

Assim, ouso demodelo desimulação para estimar as mudanças na dinâmica do COT e dos compartimentos de $\mathrm{C}$ tem sido importante. A maior parte dos modelos inclui compartimentos de $C$ de diferentes reatividades, tais como: o compartimento ativo ou lábil, com um rápido tempo de ciclagem ( $<10$ anos), geralmente representado pelo $C$ da biomassa mi crobiana (Paul, 1984); o compartimento Iento ou intermediário(100-1.000 anos), quetem sido representado pelo $\mathrm{C}$ da fração leve (Motavalli et al., 1994) ou pelo C da matéria orgânica particulada (Cambardella \& Elliot, 1992), e o compartimento passivo (>1.000 anos), que pode ser estimado pelas substâncias húmicas (Woomer et al., 1994; Leite et al., 2003).

O modelo Century (Parton et al., 1987) foi desenvol vido com o objetivo de simular a dinâmica deC ede nutrientes ( $N$, P eS) etem sidoamplamente testado e aplicado em diversos biomas naturais e cultivados, especialmente sob solos de clima temperado (F alloon \& Smith, 2002). As principais variáveis de entrada do modelo são: temperatura do ar, precipitação mensal, conteúdo de lignina do material vegetal, teores de $\mathrm{N}, \mathrm{P}$ e S do material vegetal, textura do solo, aporte de $\mathrm{N}$ do solo e da atmosfera eteor inicial de C, N, P e S nos diferentes compartimentos do solo. O modelo contém vários submodelos, a saber: o submodelo de água, o submodelo de produção vegetal e o submodelo de dinâmica da matéria orgânica do solo, baseado em múltiplos compartimentos com diferentes características de decomposição ou taxas de transformação (ex.: ativo, lento e passivo). Apesar do sucesso na aplicação do modelo Century, especialmente em sol os de clima temperado (Kelly et al., 1997; Del Grosso et al., 2001), são escassos os estudos em condições tropicais e subtropicais (M otavalli et al., 1994), principalmenteem sistemas agrícolas sob adubação orgânica combinada ou não com mineral.

Os obj etivos deste estudo foram: (a) simular, por meio do modelo Century, os efeitos de sistemas de produção de milho, sob adubação orgânica e mineral, sobre a dinâmica da matéria orgânica em um Argissolo Vermel ho-Amarelo, e (b) comparar os estoques de $\mathrm{C}$ orgânico total (COT), N total (NT) e dos compartimentos de $\mathrm{C}$ medidos por meio de métodos de laboratório e estimados pelo modelo Century na camada superficial $(0-20 \mathrm{~cm})$.

\section{MATERIAL E MÉTODOS}

O experimento está localizado na Estação Experimental da Universidade Federal de Viçosa, no município de Coimbra (MG) (20。45' S e $42 \circ 51$ ' W; altitude de 700 m) em um Argissolo Vermelho-Amarelo. A temperatura média anual é de $19{ }^{\circ} \mathrm{C}$ ea precipitação média anual é de $1.400 \mathrm{~mm}$, concentrada nos meses de outubro a março, com média anual de umidade relativa do ar de $85 \%$. Como referência de um sistema em estado de equilíbrio, col etaram-se amostras de solo da única área remanescente sob floresta secundária (Floresta Atlântica), adjacente ao experimento e sob o mesmo microdima. As propriedades químicas e físicas do solo, na camada de 0-20 cm, tanto na área experimental quanto na Floresta Atlântica, foram determinadas (Quadro 1).

A área experimental, originalmentesob Floresta Atlântica, foi desmatada em 1930 e cultivada anualmente, durante 54 anos, com as culturas de milho e de feijão no sistema de preparo convencional (aração com arado de discos, seguida de duas gradagens com grade leve niveladora). $\mathrm{O}$ experimento foi iniciado em 1984 einstalado em um arranjo fatorial com as parcelas ( $8 \times 8 \mathrm{~m})$, dispostas em um delineamento em blocos casualizados, e constituído de seis tratamentos e quatro repetições. Os tratamentos constaram de combinações entre duas doses de adubo orgânico (esterco bovino com palha de soja e de feijão), correspondentes a 0 e $40 \mathrm{~m}^{3} \mathrm{ha}^{-1}$ (AO), e três de adubo mineral, correspondentes a 0, 250 (AM 1) e $500 \mathrm{~kg} \mathrm{ha}^{-1}$ (AM 2) da fórmula 4-14-8, correspondendo, em 16 anos, à aplicação acumulada de 160, 560 e $320 \mathrm{~kg} \mathrm{ha}^{-1}$ de $\mathrm{N}, \mathrm{P}_{2} \mathrm{O}_{5}$ eK ${ }_{2} \mathrm{O}$, respectivamente, para a menor dose, e 320, 1.120 e $640 \mathrm{~kg} \mathrm{ha}^{-1}$, para a maior dose. Em AM 1, foram feitas aplicações de $20 \mathrm{~kg} \mathrm{ha}^{-1}$ de $\mathrm{N}$ e 
em AM2 $40 \mathrm{~kg} \mathrm{ha}^{-1}$ de $\mathrm{N}$ em cobertura. O adubo orgânico apresentou em média $380 \mathrm{~g} \mathrm{~kg}^{-1}$ água, $0,36 \mathrm{~g} \mathrm{~cm}^{-3}$ de densidade e teores de $\mathrm{P}, \mathrm{K}, \mathrm{Ca}, \mathrm{Mg}$ e $\mathrm{N}$ de 0,$7 ; 2,8 ; 1,0 ; 0,4$ e3,2 dag $\mathrm{kg}^{-1}$, respectivamente. A relação C:N do composto orgânico foi de 5 .

A amostragem do sol ofoi realizada após a col heita de grãos com os restos culturais mantidos sobre o solo. Na camada de $0-20 \mathrm{~cm}$, foram coletadas, na área experimental, oitoamostras de sol o para formar uma amostra composta por repetição, e, na área sob Floresta Atlântica, 15 amostras simples por área delimitada (quatro áreas de $4 \times 4 \mathrm{~m}$ distanciadas $20 \mathrm{~m}$ uma da outra). As amostras foram secas ao ar, destorroadas e passadas em peneira de malha de $2 \mathrm{~mm}$. U ma subamostra (em torno de $100 \mathrm{~g}$ ) foi separada eacondicionada sob refriger ação $\left(4\right.$ a $\left.8^{\circ} \mathrm{C}\right)$, para determinar o $\mathrm{C}$ da biomassa microbiana.

O C orgânico total (COT) foi obtido por meio de oxidação úmida com a mistura de dicromato de $\mathrm{K}$ e ácido sulfúrico sob aquecimento (Yeomans \& Bremner, 1988). O N total (NT) foi quantificado nas amostras de sol o submetidas à digestão sulfúrica e dosadas por destilaçãoK jel dhal (Bremner, 1996). A biomassa microbiana foi determinada pelo método da irradiação-extração, utilizando forno de microondas (freqüência de $2.450 \mathrm{M} \mathrm{Hz}$, energia a 900W por 180 segundos) (Islam \& Weil, 1998). O extrator utilizado foi $\mathrm{K}_{2} \mathrm{SO}_{4} 0,5 \mathrm{~mol} \mathrm{~L}^{-1}$, eoC contido nos extratos foi quantificado por meio de procedimento por oxidação úmida (Yeomans \& Bremner, 1988). O fator de conversão $\left(K_{C}\right)$ usado para converter o fluxo de $\mathrm{C}$ para $\mathrm{C}$ da biomassa microbiana foi de 0,33 (Sparling \& West, 1988). O C da biomassa microbiana $\left(C_{\text {MIC }}\right.$ ) foi usado como estimativa do compartimento ativo da matéria orgânica (Paul, 1984; Motavalli et al., 1994).

A fração leve da matéria orgânica do solo foi isolada por flotação em solução de iodeto de $\mathrm{Na}$, densidade de $1,8 \mathrm{~g} \mathrm{~cm}^{-3}$, como proposto por Sohi et al. (2001) e Machado (2002). O material obtido foi seco em temperatura de $80^{\circ} \mathrm{C}$ por $72 \mathrm{~h}$. O C da fração leve $\left(C_{F L}\right)$ foi quantificado por combustão via seca em analisador Perkin E Imer CHNS/O 2400 eusado como estimativa do compartimento lento (Cambardella \& Elliot, 1992). O compartimento passivo da matéria orgânica foi calculado pelo C orgânico total menos a soma dos compartimentos ativo e lento.

Os valores de densidade do solo, apresentados por Galvão (1988) e determinados neste trabalho, foram utilizados para calcular os estoques de COT e NT e de compartimentos de $C$ em equivalência com a massa de solo (Carter et al, 1998; Leite, 2002).

O modelo Century foi desenvolvido e testado principal mente com dados originários de pastagens e agricultura no sistema trigo-pousio em pradarias norte-americanas (Parton et al., 1987; 1988). Para realizar avaliações mais criteriosas acerca das predições do modelo, os valores das variáveis determinados a partir destes estudos prévios foram inalterados. Essas variáveis gerais ou não específicas dos locais estudados incluem a taxa de decomposição máxima para cada compartimento, as constantes que dividem os fluxos dos produtos de decomposição eas variáveis que controlam os efeitos da textura do solo, da relação lignina/N, da temperatura e da umidade na decomposição da matéria orgânica do solo.

As variáveis de entrada específicas do local, tais como: textura do solo (teores de areia, siltee argila), densidade do solo e teores de COT e NT e dos compartimentos de C foram obtidas no experimento. As médias mensais das temperaturas máxima e mínima do ar epreci pitação mensal de 1967 até 2000 foram obtidas na Estação Meteorológica da Universidade F ederal de Viçosa. A quantidade de C adicionada por meio do adubo orgânico aplicado aos tratamentos, a relação C/N e C/P (Galvão, 1995) e o teor de lignina deste composto (Palm et al., 2001) também foram usados como variáveis de entrada (Quadro 2).

Quadro 1. Propriedades químicas e físicas do solo na camada de 0-20 cm

\begin{tabular}{|c|c|c|c|c|c|c|c|}
\hline Tratamento & $\mathbf{p H ~} \mathbf{H}_{2} \mathrm{O}$ & СОТ & NT & Argila & Areia & Silte & ds \\
\hline & & & 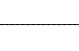 & dag $\mathrm{kg}^{-1}$ & 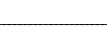 & - & $\mathrm{Mg} \mathrm{m}^{-3}$ \\
\hline 0 & 5,86 & 1,78 & 0,15 & 66 & 19 & 15 & 1,03 \\
\hline AM 1 & 5,61 & 2,02 & 0,16 & 75 & 10 & 15 & 0,99 \\
\hline AM 2 & 5,25 & 1,96 & 0,15 & 70 & 16 & 14 & 1,02 \\
\hline $\mathrm{AO}$ & 6,38 & 2,29 & 0,17 & 74 & 10 & 16 & 1,04 \\
\hline$A M 1+A O$ & 6,15 & 2,42 & 0,18 & 77 & 10 & 13 & 1,06 \\
\hline$A M 2+A O$ & 5,85 & 2,36 & 0,21 & 69 & 18 & 13 & 1,05 \\
\hline Floresta Atlântica & 5,48 & 2,83 & 0,22 & 46 & 37 & 17 & 1,13 \\
\hline
\end{tabular}

COT = carbono orgânico total, NT = nitrogênio total, ds = densidade do solo. 0 =testemunha; AM 1 (adubo mineral 1 ) = 250 kg ha ${ }^{-1}$ de 4-14-8 + $20 \mathrm{~kg} \mathrm{ha}^{-1}$ de N em cobertura; AM2 (adubo mineral 2) = $500 \mathrm{~kg} \mathrm{ha}^{-1}$ de 4-14-8 $+40 \mathrm{~kg} \mathrm{ha}^{-1} \mathrm{em}^{\mathrm{cobertura}}$; AO = adubo orgânico, $40 \mathrm{~m}^{3} \mathrm{ha}^{-1}$. 
Quadro 2. Variáveis de entrada usadas nas simulações com o modelo Century v .4.0

\begin{tabular}{|c|c|}
\hline Solo & \\
\hline Textura (areia, silte, argila) (\%) & $38,16,46$ \\
\hline Densidade do solo $\left(\mathrm{Mg} \mathrm{m}^{-3}\right)$ & 1,13 \\
\hline \multicolumn{2}{|l|}{ MOS(1) inicial $\left(\mathrm{g} \mathrm{C} \mathrm{m}^{-2} ; \mathrm{C}: \mathrm{N}\right)$} \\
\hline C ativo & $159 ; 9$ \\
\hline C Iento & $1.776 ; 22$ \\
\hline C passivo & $4.460 ; 12$ \\
\hline \multicolumn{2}{|l|}{ Clima } \\
\hline Precipitação média (mm/mês) & 120 \\
\hline Temperatura média máxima $\left({ }^{\circ} \mathrm{C}\right)$ & 14,8 \\
\hline Temperatura média mínima $\left({ }^{\circ} \mathrm{C}\right)$ & 26,4 \\
\hline \multicolumn{2}{|l|}{ Matéria orgânica } \\
\hline Carbono do adubo orgânico ( $\left.\mathrm{g} \mathrm{m}^{-2}\right)$ & 144 \\
\hline Relação C/N do adubo orgânico & 5 \\
\hline Relação C/P do adubo orgânico & 22 \\
\hline Teor de lignina do adubo orgânico (\%) & 10 \\
\hline
\end{tabular}

(1) Matéria orgânica do solo (profundidade de 0-20 cm).

Os estoques de COT, NT e dos compartimentos de C (ativo, lento e passivo) foram obtidos por meio dos dois métodos: indireto e direto. No método indireto, esses estoques foram estimados por meio desimulação de equilíbrio delongo prazo (6000 anos) e usados como variáveis de entrada para as simulações que estimaram as mudanças no uso da terra. Para cada tratamento, o modelo simulou a dinâmica da matéria orgânica do sol o por um período de 53 anos (1930-1983), representando a derrubada da floresta e a conversão para as culturas de milho e de feijão e, subseqüentemente, por um período de 66 anos (1984-2050), caracterizando a adoção dos tratamentos com adubação mineral e orgânica. No método direto, os valores iniciais para os compartimentos de $\mathrm{C}$ foram obtidos no solo sob Floresta Atlântica por meio de métodos de laboratório e usados de forma similar ao método indireto. Todas as estimativas feitas pelo modelo Century foram baseadas na camada de $0-20 \mathrm{~cm}$. No ano de 2000, os valores simulados e observados de COT, NT e dos compartimentos de C ativo, lento e passivo foram submetidos à análise de regressão linear ecorrelação de Pearson, cuja significância dos coeficientes foi determinada pel o testet de Student a 5 e $1 \%$.

\section{RESULTADOS E DISCUSSÃO}

\section{Estimativa dos compartimentos de carbono por meio da simulação de equilíbrio}

Os estoques de COT e de $\mathrm{C}$ no compartimento passivo aumentaram durante a simulação de equilíbrio, de 6000 anos, realizada pelo modelo
Century (Figura 1). Após esse período, o estoque de COT foi de $79 \mathrm{Mg} \mathrm{ha}^{-1}$, i.e., $23 \%$ maior do queaquele medido no solo sob Floresta Atlântica, enquanto o de $\mathrm{C}$ no compartimento passivo foi de $44 \mathrm{Mg} \mathrm{ha}^{-1}$ (56 \% COT), diferença de 1,3 \% em rel ação ao estoque de C medido no solo sob Floresta Atlântica (Quadro 3). Os estoques de C no compartimento ativo (2,1 $\mathrm{Mg} \mathrm{ha}^{-1}$; $3 \%$ COT) e lento (33 $\mathrm{Mg} \mathrm{ha}^{-1}$; $42 \%$ COT) mantiveram-se constantes durante a simulação de equilíbrio (Figura 1) e apresentaram, respectivamente, 31 e 86 \% de diferença em relação àqueles medidos no solo sob Floresta Atlântica (Quadro 3).

Os estoques de COT simulados pelo modelo Century durante 120 anos diminuíram após a mudança da floresta para agricultura (Figura 2a). No ano de 1984, início do experimento, o estoque de COT foi de $39 \mathrm{Mg} \mathrm{ha}^{-1}$, i.e., redução de $50 \%$ em relação aos estoques iniciais no solo sob Floresta Atlântica (79 $\left.\mathrm{Mg} \mathrm{ha}^{-1}\right)$. Este decréscimo pode ser atribuído ao manejo adotado pelos agricultores, calcado em sistemas de preparo convencionais, envolvendo aração e gradagem, que maximizam a oxidação do C, e aos sistemas de culturas, com

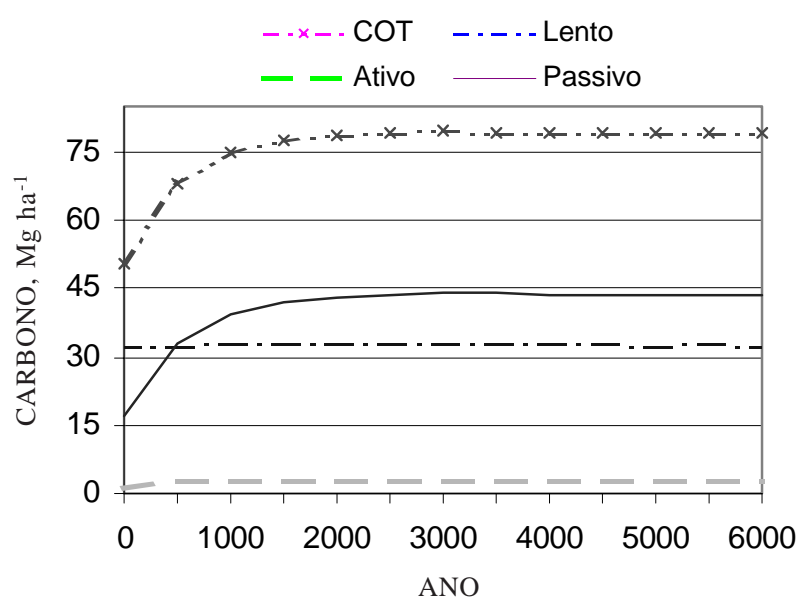

Figura 1. E stoques de carbono orgânico total (COT) e dos compartimentos de carbono orgânico de um Argissolo Vermelho-Amarelo (0-20 cm), obtidos por meio da simulação de equilíbrio realizada pelo modelo Century.

Quadro 3. Estoques medidos de carbono orgânico total (COT) e de carbono (C) nos comparti mentos ativo, lento e passivo no solo sob F loresta Atlântica

\begin{tabular}{lc}
\hline Compartimento & Estoque \\
\hline & Mg ha-1 $^{-1}$ \\
COT & 63,9 \\
C Ativo & 1,6 \\
C Lento & 17,7 \\
C Passivo & 44,6 \\
\hline
\end{tabular}


reduzido aporte de resíduos, que diminuem a entrada de $\mathrm{C}$ no solo. As diferenças observadas entre os estoques de COT do solo sob agricultura e sob Floresta Atlântica devem ser interpretadas com cuidado, pois, embora os dois ecossistemas estejam próximos sob o mesmo mi croclima, os menores teores de argila do solo sob floresta limitam a capacidade deste ecossistema em acumular mais C no solo.

Hassink (1997), avaliando as relações entre a proporção de partículas finas (ex.: partículas de argila esilte menores do que $20 \mu \mathrm{m}$ ) de solos declima tropical e de clima temperado, constatou que o solo tem capacidade de preservar $\mathrm{C}$ e $\mathrm{N}$ pela associação com partículas de argila e silte, que o $\mathrm{C}$ e $\mathrm{N}$ associados a estas partículas mais finas são protegidos da ação microbiana eque o acúmulo deC eN nestas partículas mais finas élimitado. Em 2000, 16 anos após a adoção dos tratamentos, os estoques de COT não se recuperaram mesmo com os solos sob cultivo apresentando mai or teor de argila do que o sol o sob fl oresta, tendo sido esses estoques menores no solo sob tratamentos sem adubação orgânica (37 $\mathrm{Mg} \mathrm{ha}^{-1}$ ) do que no solo sob tratamentos com adubação orgânica (40 $\left.\mathrm{Mg} \mathrm{ha}^{-1}\right)$. Esses resultados concordam com os verificados por Liang et al. (1996), em estudos com adubação orgânica e mineral, também com o modelo Century e, provavelmente, foram devidos ao maior retorno de $\mathrm{C}$ e $\mathrm{N}$ ao solo nos tratamentos com aporte orgânico (dados não apresentados).

Similarmente ao COT, o model o Century estimou diminuição nos estoques de $C$ no compartimento ativo (Figura 2b) após a derrubada da Floresta Atlântica. No ano de 1984, o estoque de C no compartimento ativo foi de $0,11 \mathrm{Mg} \mathrm{ha}^{-1}$, o que representa uma perda de 95 \% em relação ao estoque de C inicial estimado pel o modelo para o solo sob F loresta Atlântica. No model o Century, o compartimento ativo, associado à biomassa microbiana, apresentou curto tempo de reciclagem e mai or sensi bilidadeàs ações antrópicas e às al terações de manejo do que o COT (Powlson et al., 1987), o que contribuiu para perdas de maior magnitude. Em 2000, os estoques de C no compartimento ativo aumentaram para 0,18, 0,21, $0,31,0,36$ e $0,40 \mathrm{Mg} \mathrm{ha}^{-1}$, nos tratamentos AM 1, $A M 2, A O, A M 1+A O$ eAM 2 + AO, respectivamente. $O$ aumento no tamanho do compartimento ativo em tratamentos com adubação orgânica, comparativamente aos tratamentos sem adubação orgânica, foi também observado por Paustian et al. (1992).

No compartimentolento, o estoque de $C$ no início do experimento foi de 1,6 $\mathrm{Mg} \mathrm{ha}^{-1}$, redução de 91 \% em relação ao estimado pel o model o Century para o solo sob Floresta Atlântica (Figura 2c). Após 16 anos, os estoques de $C$ aumentaram apenas nos tratamentos AO $\left(3,6 \mathrm{Mg} \mathrm{ha}^{-1}\right), \quad A O+A M 1$ $\left(4,0 \mathrm{Mg} \mathrm{ha}^{-1}\right)$ eAO +AM2 $\left(4,3 \mathrm{Mg} \mathrm{ha}^{-1}\right)$, representando acréscimos de 125, 150 e $169 \%$, respectivamente, em relação aos estoques de C no início do experimento. A diminuição nos estoques de $C$ no compartimento passivo após a mudança da Floresta Atlântica para agricultura foi demenor intensidade do que nos demais compartimentos ativo e lento (Figura 2d). Hassink (1997) também constatou menor diminuição de $\mathrm{C}$ e $\mathrm{N}$ associados à argila e ao silte em relação ao $\mathrm{C}$ e $\mathrm{N}$ associados a frações superiores a $20 \mu \mathrm{m}$ de diversos solos tropicais e de clima temperado e concluiu que as partículas de argila e de silte protegem o C da degradação promovida por microrganismos do solo.

\section{Estimativa dos compartimentos de carbono por meio dos valores medidos}

A diminuição nos estoques de COT e de $\mathrm{C}$ nos compartimentos (ativo, lento e passivo) também foi constatada no método direto. O estoque de COT, estimado para o início do experimento, foi de $40 \mathrm{Mg} \mathrm{ha}^{-1}, 37 \%$ de perda em relação ao estoque inicial no solo sob F loresta Atlântica (Figura 3a). No ano de 2000, os estoques de COT nos solos sob tratamento-testemunha, AM 1, AM2, AO, AM 1+AO e AM 2+AO foram de 36,8, 37,7, 38,1, 40,2, 40,8 e $41,1 \mathrm{Mg} \mathrm{ha}^{-1}$, respectivamente, o que indica um balanço equilibrado entre adições e perdas de $C$ nos tratamentos com a presença da adubação orgânica. Esses resultados concordam com os obtidos por meio da simulação de equilíbrio. Kelly et al. (1997), utilizando o modelo Century para estimar mudanças no $C$ orgânico de solos de vários experimentos de longo prazo da Europa, também constataram que as estimativas dos estoques de COT oferecidas pelo model o Century foram maiores para os tratamentos que receberam adubação orgânica, no caso esterco, em relação aos tratamentos que receberam apenas adubação mineral.

No compartimento ativo, similarmente ao verificado no método indireto, o estoque de $C$ foi de $0,11 \mathrm{Mg} \mathrm{ha}^{-1}$, perda de $93 \%$ em relação aos estoques iniciais medidos no solo sob Floresta Atlântica (F igura 3b). No entanto, a adoção dos tratamentos, especial mente com adubação orgânica, recuperou os estoques de $C$, os quais, após dezesseis anos, aumentaram para 0,30 (AO), 0,38 (AO + AM 1) e $0,40 \mathrm{Mg} \mathrm{ha}^{-1}$ (AO +AM2). No compartimentolento, o estoque de $C$ no início do experimento foi de 1,6 $\mathrm{Mg} \mathrm{ha}^{-1}$, similar ao observado no método indireto, e representou redução de 91 \% em rel açãoao estoque medido no solo sob Floresta Atlântica (Figura 3C). No ano de 2000, os estoques de $C$ do compartimento lento no sol o sob os tratamentos $0, A M 1, A M 2, A O$, $\mathrm{AM} 1$ + $\mathrm{AO}$ e AM2 + AO foram de 1,0, 1,6, 1,9, 3,7, 4,1 e 4,4 $\mathrm{Mg} \mathrm{ha}^{-1}$, respectivamente, indicando ganho de $C$ nos sistemas com a presença de adubação orgânica de 130 a 175 \% em relação ao estoque de C do compartimento lento no início do experimento. De forma similar ao método indireto, foram observados menores decréscimos nos estoques de $C$ do compartimento passivo desde a derrubada da Floresta até o início do experimento (Figura 3d). 
(a)

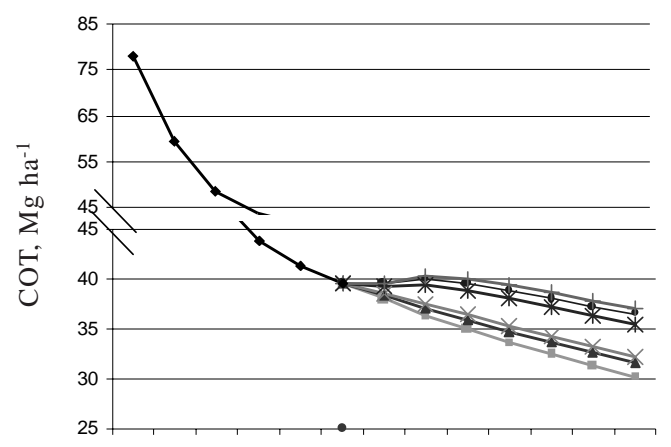

(c)

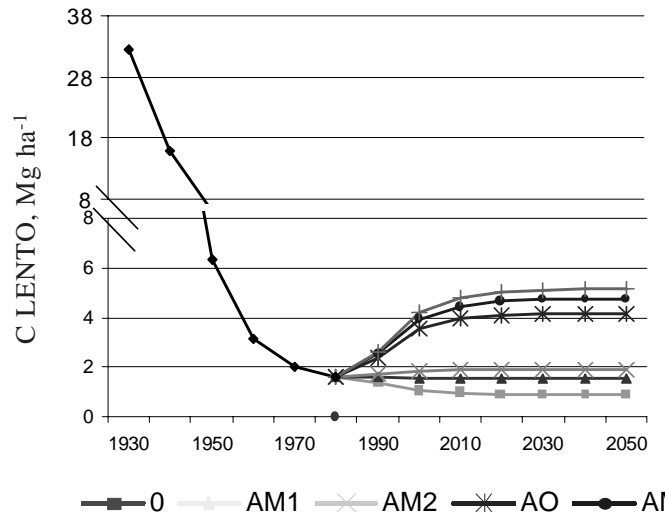

(b)

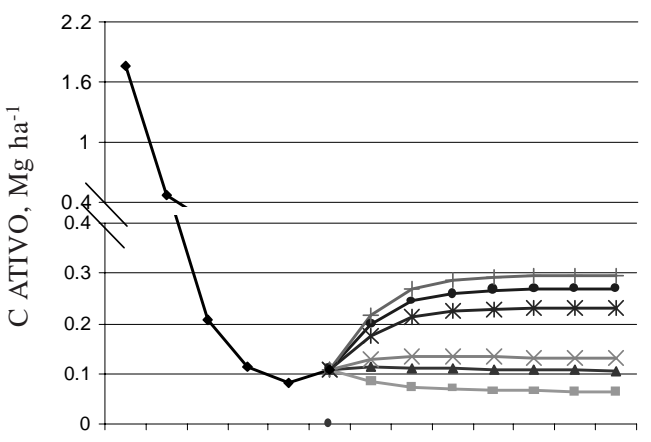

(d)

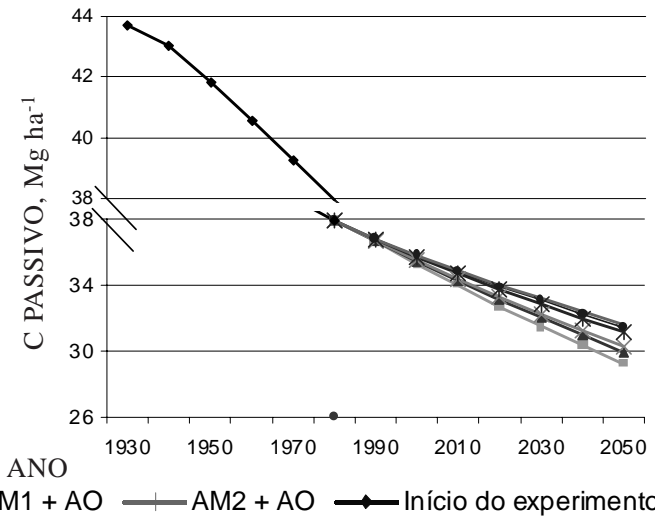

F igura 2. Estoques de carbono orgânico total (COT) (a) e de carbono nos compartimentos: ativo (b), lento (c) e passivo (d), simulados pelo modelo Century por meio do método indireto nos seguintes tratamentos: $0=$ testemunha; AM1 (adubo mineral 1) $=250 \mathrm{~kg} \mathrm{ha}^{-1} \mathrm{de}^{4-14-8}+20 \mathrm{~kg} \mathrm{~N} \mathrm{ha}^{-1} \mathrm{em}_{\text {cobertura; }}$ AM2 (adubo mineral 2) $=500 \mathrm{~kg} \mathrm{ha}^{-1}$ de 4-14-8 $+40 \mathrm{~kg} \mathrm{ha}^{-1}$ de $\mathrm{N}$ em cobertura; $A O$ = adubo orgânico, $40 \mathrm{~m}^{3} \mathrm{ha}^{-1} ;$ AM1 + AO e AM2 + AO.

Os estoques de COT e de $\mathrm{C}$ nos compartimentos (ativo, lento e passivo), tanto por meio da simulação de equilíbrio quanto por meio dos valores medidos, foram reduzidos após a mudança da F loresta para agricultura, graças, principalmente, ao sistema de preparo do solo convencional, com aração e gradagem. O revol vimento do sol o pel a aração e por várias gradagens niveladoras promove maior aeração do sol o da camada arável (normalmente até $18-20 \mathrm{~cm}$ ) e incorporação de resíduos vegetais em profundidade, causando maior atividade de microrganismos que atuarão na decomposição de $C$ do solo (Reicosky et al., 1995). A diminuição nos estoques de $\mathrm{C}$ ocorreu tanto nos compartimentos ativos e lentos como nos passivos, embora esteúltimo em menor magnitude, em virtude da proteção promovida pela argila e silte. No entanto, a adoção dos tratamentos com adubação orgânica a partir de 1984 aumentou os estoques de C, especial mente no compartimento lento, em razão da maior influência das mudanças no manejo neste compartimento.

\section{Estimativa doscompartimentos de $\mathrm{N}$ erelação $\mathrm{C} \mathbf{N}$}

Os estoques de NT, similarmente ao observado nos estoques de COT, diminuíram após a substituição da floresta pela agricultura (F igura 4a). No ano de 1984, o estoque de NT foi de 3,3 $\mathrm{Mg} \mathrm{ha}^{-1}$, i.e., perda de $1,6 \mathrm{Mg} \mathrm{ha}^{-1}$ (33\%) em relação ao estoque estimado pelo modelo Century para o solo sob Floresta Atlântica. No entanto, a adoção do sistema AM2 + AO possibilitou a recuperação dos estoques de NT. No ano de 2000, os estoques de NT nos solos sob a testemunha e sob o tratamento com adubação orgânica foram de 3,1 e3,5 M g ha-1, respectivamente.

A diminuição nos estoques de $\mathrm{N}$ no compartimento ativo, durante o período em que a área estava sob uso dos agricultores (1930-1983), foi de maior intensidade do queaquela observada nos estoques deNT, decorrente da maior sensibilidade da biomassa microbiana, que representa o compartimento ativo, às mudanças no manejo.

No início do experimento, o estoque de $\mathrm{N}$ no compartimento ativo foi de $0,03 \mathrm{Mg} \mathrm{ha}^{-1}$, aproximadamente $90 \%$ inferior ao do estoque estimado pel o modelo para o solo sob Floresta Atlântica (Figura 4b). O tratamento AM2 + AO aumentou os estoques de $\mathrm{N}$ no compartimento ativo em relação ao início do experimento, provavelmente por causa das maiores quantidades de $\mathrm{N}$ adicionadas pelo adubo mineral. 
(a)

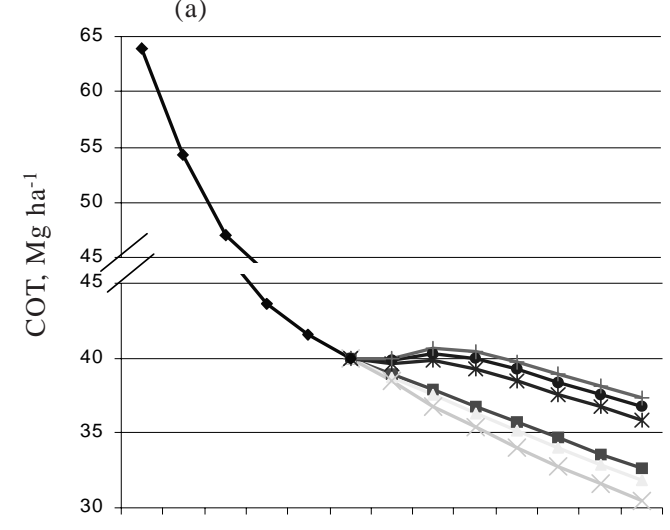

(c)

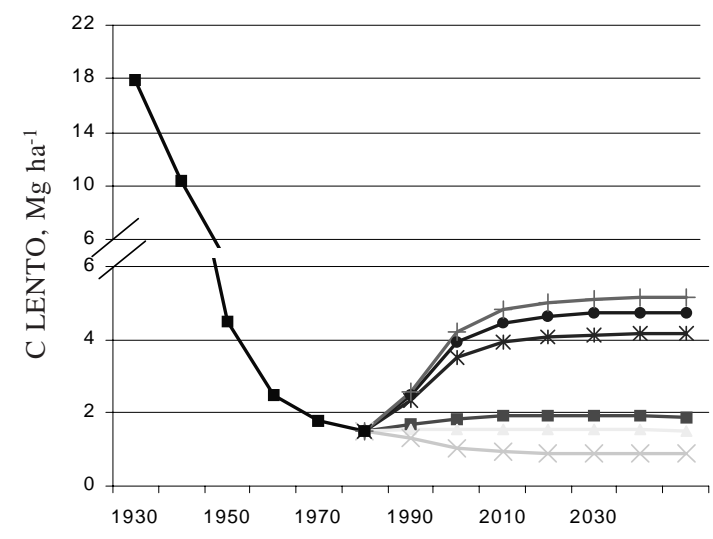

(b)

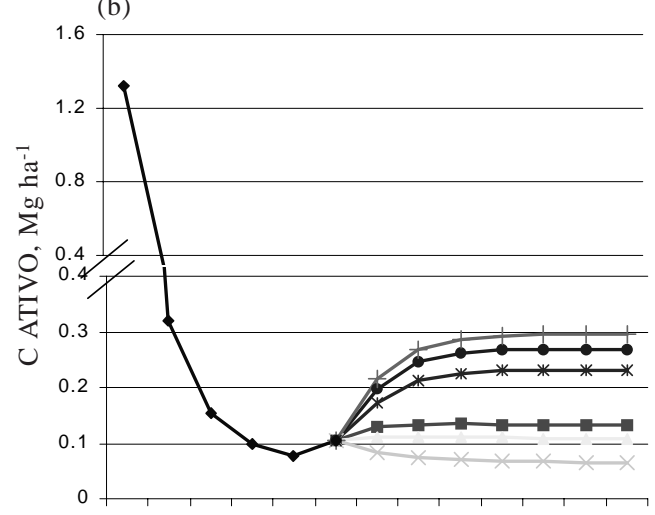

(d)

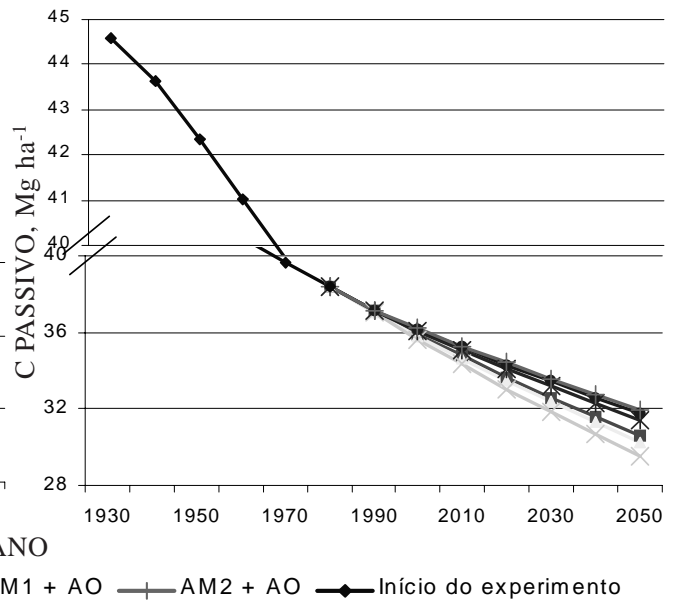

Figura 3. Estoques de carbono orgânico total (COT) (a) e de carbono nos comparti mentos: ativo (b), lento (c) e passivo (d), simulados pelo modelo Century por meio do método direto nos seguintes tratamentos: 0 (testemunha); AM1 (adubo mineral 1 ) $=250 \mathrm{~kg} \mathrm{ha}^{-1} \mathrm{de} \mathrm{4-14-8}+20 \mathrm{~kg} \mathrm{ha}^{-1} \mathrm{de} \mathrm{N}$ em cobertura; AM2 (adubo mineral 2) $=500 \mathrm{~kg} \mathrm{ha}^{-1}$ de 4-14-8 $+40 \mathrm{~kg} \mathrm{ha}^{-1} \mathrm{de} \mathrm{N} \mathrm{em} \mathrm{cobertura;} \mathrm{AO} \mathrm{=adubo} \mathrm{orgânico,} 40 \mathrm{~m}^{3} \mathrm{ha}^{-1}$; AM1 + AO e AM2 + AO.

No ano de 2000, os estoques no sol o sob os tratamentos sem e com a presença da adubação orgânica foram de 0,02 e 0,12 $\mathrm{Mg} \mathrm{ha}^{-1}$, respectivamente, o que ressalta a importância da adubação orgânica na recuperação dos estoques de N. No ano de 1984, o estoque de $C$ no compartimento lento foi de $0,12 \mathrm{Mg} \mathrm{ha}^{-1}$, redução de $86 \%$ em relação àquele verificado no sol o sob Floresta Atlântica e, em 2000, os estoques de $\mathrm{N}$ nos tratamentos: testemunha e AM 2 + AO foram, respectivamente, de 0,07 e $0,28 \mathrm{Mg} \mathrm{ha}^{-1}$, evidenciando a recuperação desses estoques notratamento com adubo orgânico (F igura 4c).

No compartimento passivo, as variações desde a mudança da floresta para agricultura foram menos expressivas, diminuindo de $3,5 \mathrm{Mg} \mathrm{ha}^{-1}$ de $\mathrm{C}$ para cerca de $3 \mathrm{Mg} \mathrm{ha}^{-1}$ de $\mathrm{C}$ em ambos os tratamentos (Figura $4 d$ ). A relação C:N do compartimento ativo variou de quatro a oito, durante o período simulado tanto na testemunha (Figura 5a) quanto no tratamento AM2 + AO (Figura 5b). No compartimento lento a relação $\mathrm{C}: \mathrm{N}$ foi maior, flutuando de 22 a 16 também em ambos os tratamentos. A maior estabilidade do compartimento passivo causou a menor variação observada na relação C:N (Figura 5).

\section{Comparação de valores medidos e simulados pelo modelo Century.}

As diferenças entre estoques de COT, medidos e simulados pelo model o Century nos tratamentos 0 , AM 1 e AM2, foram de 0,05, 4,3 e 4,5\% respectivamente (Figura 6a), corroborando os resultados dos estudos desenvol vidos por Liang et al . (1996): a grande possibilidade do model o em simular COT em solos de clima tropical. Nos tratamentos com a presença da adubação orgânica, esses estoques foram subestimados em torno de $17 \%$, o que pode ser atribuído à ausência no modelo dos mecanismos que controlam a exsudação de $C$ pelas raízes e seu metabolismo microbiano, intensamente presentes em sol os sob adubação orgânica. Além disso, a ausência no modelo da mineralogia, predominantemente 
(a)

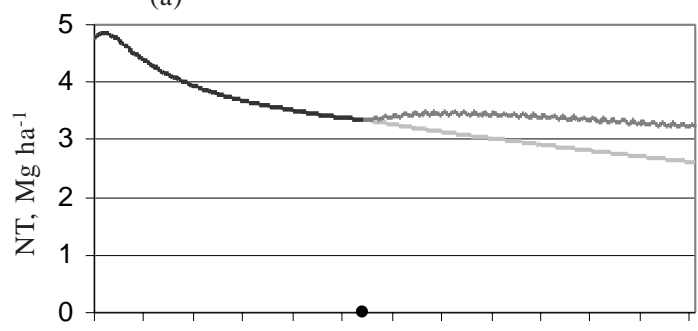

(c)

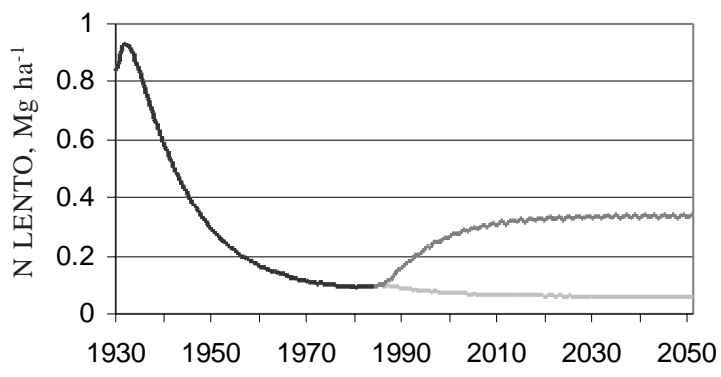

(b)

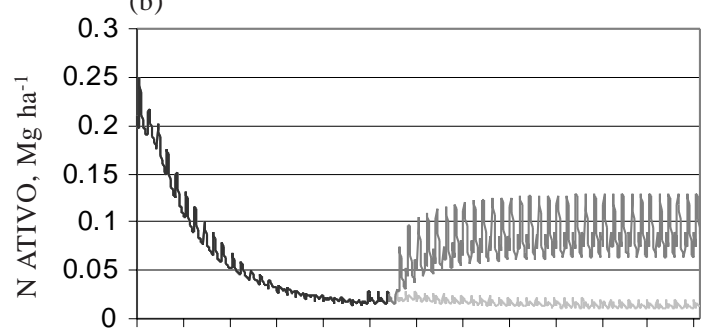

(d)

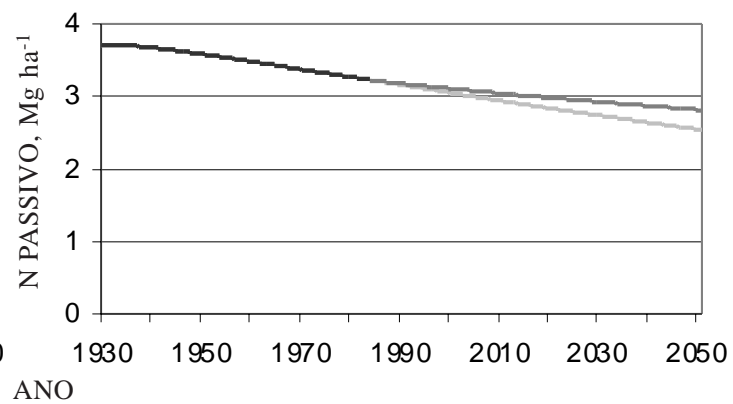

- Período anterior ao experimento

Figura 4. Estoques de nitrogênio total (NT) (a) e dos compartimentos de nitrogênio, ativo (b), lento (c) e passivo (d) $(0-20 \mathrm{~cm})$, nos tratamentos: 0 (testemunha) e AM2 + AO (500 $\mathrm{kg} \mathrm{ha}^{-1}$ de 4-14-8 + $40 \mathrm{~kg} \mathrm{ha}^{-1}$ de $\mathrm{N}$ em cobertura + adubo orgânico, $40 \mathrm{~m}^{3} \mathrm{ha}^{-1}$ ).

(a)

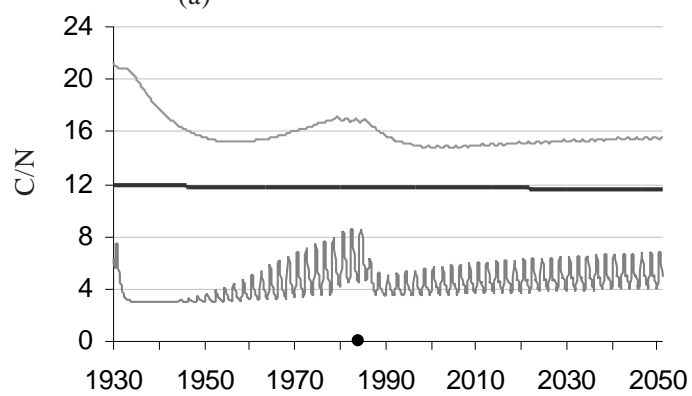

(b)

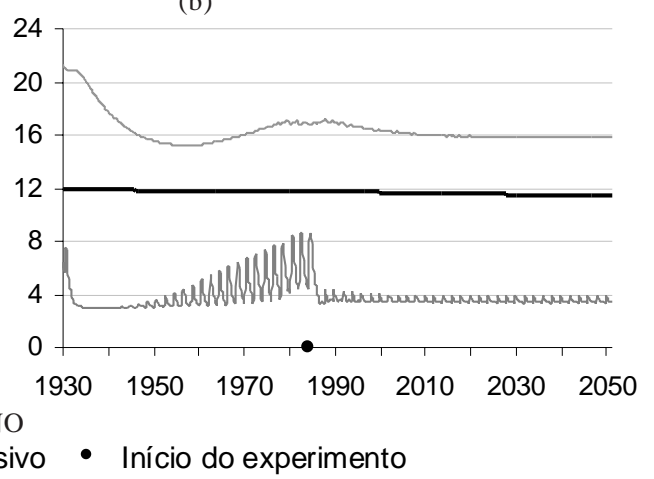

Figura 5. Relação $\mathrm{C} / \mathrm{N}$ nos compartimentos de nitrogênio, ativo, lento e passivo, nos tratamentos: 0 (testemunha) (A) e AM2 +AO (500 kg ha-1 de 4-14-8 + $40 \mathrm{~kg} \mathrm{ha}^{-1}$ de $\mathrm{N}$ em cobertura + adubo orgânico, $\left.40 \mathrm{~m}^{3} \mathrm{ha}^{-1}\right)(\mathrm{b})$.

oxídica nos solos de clima tropical que favorece a formação de complexo organomineral, podetambém ter contribuído para a subestimativa dos estoques de COT nos tratamentos com a adubação orgânica, conforme preconizado por Woomer et al. (1994). Por outrolado, Varadachari et al. (1994) relataram que a quantidade deácidos fúl vicos adicionada, que permaneceu adsorvida a diferentes minerais de argila, não se relacionou com a superfície específica das argilas. Ainda nesta linha, Hassink (1997) não constatou relação entre o tipo de mineral de argila predominante e oteor de $\mathrm{C}$ e $\mathrm{N}$ orgânicos associados às frações argila e silte. Estes resultados enfatizam o provável efeito conjunto da granulometria, princi- pal menteem solos com alto teor de argila, como neste estudo, e da mineralogia, por meio da proteção química coloidal da matéria orgânica.

Nos estoques de COT, medidos e simulados pelo modelo Century, não foram verificadas diferenças entre os tratamentos AO, AM 1 + AO e AM2 + AO. No modelo, essas diferenças são associadas a dois fatores: à qualidade da matéria orgânica (relação lignina/N) eà quantidade de $\mathrm{N}$ adicionada nas formas orgânicas einorgânicas enão há menção à forma com que este aporte orgânico é aplicado e mineralizado. Além disso, a produtividade de grãos eo aporte deC pelas culturas (dados não apresentados) nos 
tratamentos somente com adubação orgânica ou combinada com adubação mineral foram similares, contribuindo para estoques de COT também semelhantes.

No compartimento ativo, os estoques de C medidos foram maiores do que os simulados pelo modelo Century, similarmente ao observado nos trabal hos de Paustian et al. (1992) e M otavalli et al . (1994) (Figura 6b). As diferenças observadas entre os estoques medidos esimulados foram menores nos tratamentos com adubação orgânica e variaram de 50 (AM $2+A O)$ a $79 \%$ (testemunha). Os estoques de $\mathrm{C}$ medidos no compartimento lento, nos tratamentos sem a presença da adubação orgânica, foram mai ores do que os simulados pelo modelo Century. As diferenças entreval ores medidos e simulados foram de 57,38 e $17 \%$, para os tratamentos: testemunha, AM1 e AM 2, respectivamente.

Por outro lado, com a adubação orgânica, os estoques simulados no compartimento lento foram maiores do que os estoques medidos, embora com diferenças de apenas 0,5\%(AO), 7,5\% (AM 1 + AO) e $18 \%$ (AM2 + AO) (Figura 6C). I sto pode ser atribuído ao fato de ser o tempo de residência do $C$ no model o maior do que no evento real eao fato de o compartimento lento provavelmente incluir outros compostos além do C da fração leve. Pode ser também atribuído ao método de extração usado neste estudo que não extrai completamente o $C$ da fração leve em solos tropicais, como constatado por Motavalli et al. (1994).

Os estoques de $\mathrm{C}$ no compartimento passivo, medidos e simulados pelo modelo Century, foram similares nos tratamentos sem a adubação orgânica com diferenças inferiores a $5 \%$ (Figura $6 \mathrm{~d}$ ). Nos tratamentos $A O, A M 1+A O$ e $A M 2+A O$, as diferenças aumentaram para 16, 21 e $20 \%$, respectivamente. No modelo, parte do $\mathrm{C}$ adicionado por meio do composto é perdida na forma de $\mathrm{CO}_{2}$, pois não há, além da textura, mecanismos de estabilização, como o causado pel o mineral deargila ou óxidos de Fe e Al. Por outro lado, em um evento real, esse mesmo $C$ é alocado nas substâncias húmicas, aumentando, assim, o tamanho do compartimento passivo. As diferenças nos estoques de NT medidos e simulados pelo modelo Century nos tratamentos sem a presença da adubação orgânica foram restritas ao sistema AM2 (6\%), pois, na testemunha e AM2, os estoques foram similares (Figura 6e). Nos tratamentos com adubação orgânica, os estoques simulados pelo model o foram subestimados em relação aos estoques medidos, embora as diferenças tenham sido em torno de $10 \%$.

Nos estoques simulados pelo model o Century, o compartimento passivo representou cerca de $90 \%$ do COT, ou seja, muito maior do que otamanho pressuposto no modelo Century (30-50\%). Essa diferença está relacionada com a proteção à decomposição gerada pela componente mineral do solo domi- nada por caulinita e óxidos deFe, associada à textura argilosa. Por isso, parece essencial a incorporação da mineral ogia no submodel o deC. O compartimento passivo pode também ser representado pela soma das frações ácidos fúlvicos e húmicos, e
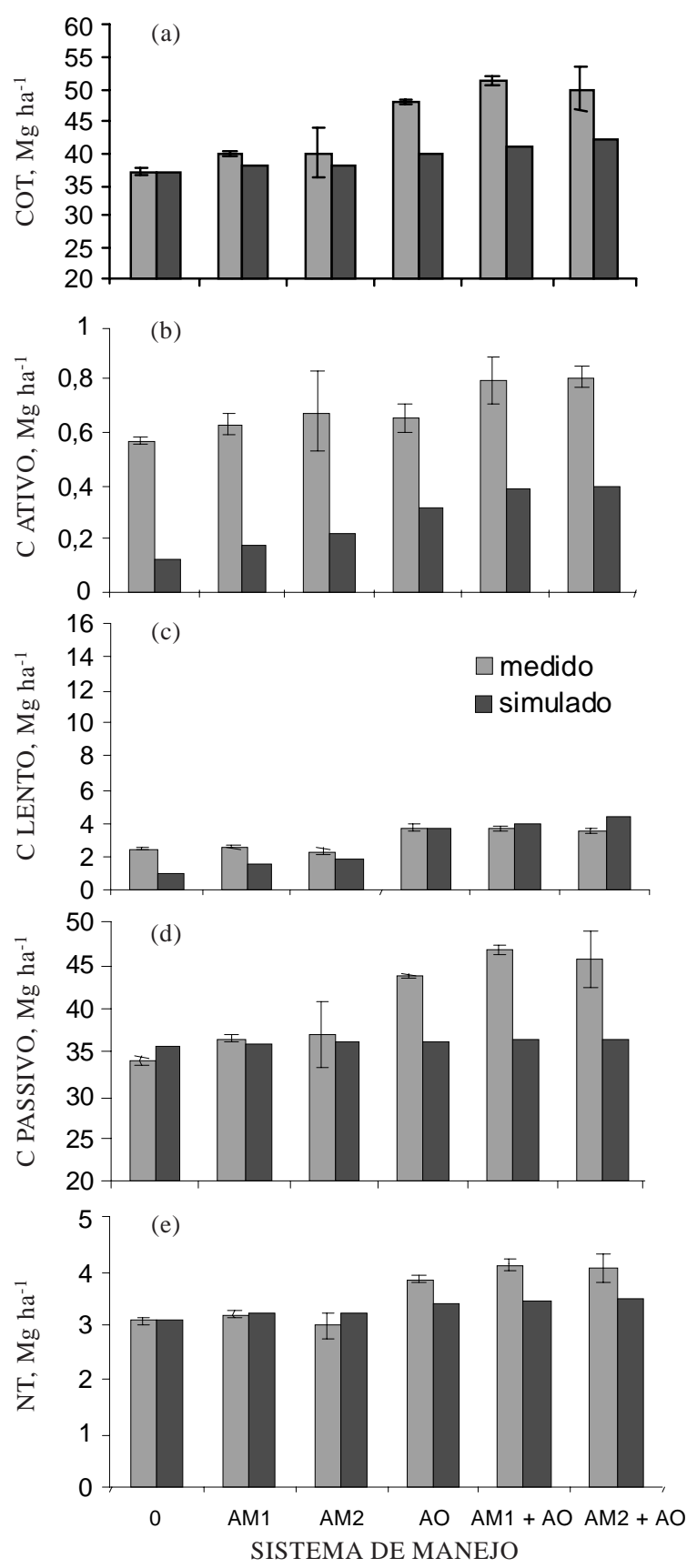

Figura 6. Comparação dos estoques de carbono orgânico total (COT) (a), dos compartimentos de carbono ativo (b), lento (c) e passivo (d) e do nitrogênio total (NT) (e), medidos e simulados pelo modelo Century nos seguintes tratamentos: 0: testemunha; AM1: $250 \mathrm{~kg} \mathrm{ha}^{-1}$ de 4-14-8 + $20 \mathrm{~kg} \mathrm{ha}^{-1}$ de $\mathrm{N}$ em cobertura; AM2: $500 \mathrm{~kg} \mathrm{ha}^{-1}$ de 4-14-8 + $40 \mathrm{~kg} \mathrm{ha}^{-1}$ de $\mathrm{N}$ em cobertura; $A O$ : adubo orgânico, $40 \mathrm{~m}^{3} \mathrm{ha}^{-1}$; AMl + AO e AM2 + AO. Para valores medidos, $n=4$. 
huminas, principalmente sena fraçãoáci dos fúlvicos forem desconsiderados os compostos orgânicos de baixo peso molecular, como evidenciado nos estudos de Leite et al. (2003). No presente estudo, todavia, pel o fato de o C e o N do compartimento passivo terem sido medidos não diretamente, mas por diferença entre o C e o N orgânicos totais e o C e N do compartimento ativo mais o compartimento lento, a verificação dos valores simulados deve ser realizada com cautela.
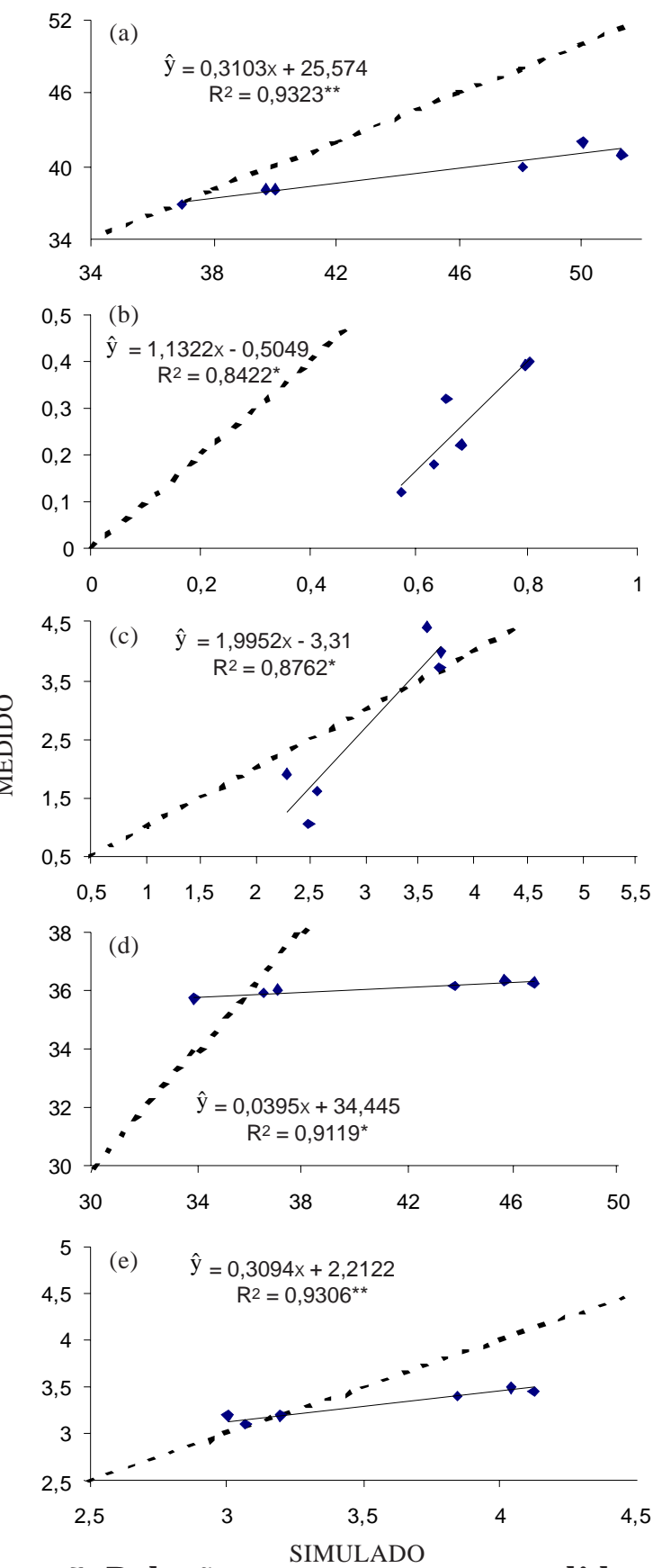

Figura 7. Relação entre estoques medidos e simulados de carbono orgânico total (a), de C nos compartimentos ativo (b), lento (c) e passivo (d) e de nitrogênio total (e). *, ** significativos a 0,05 e 0,01, respectivamente.
Os estoques de COT medidos e simulados pelo modelo Century foram correlacionados $\left(R^{2}=0,93\right.$, $p<0,01$ ), o que evidencia a potencialidade do modelo para simular a dinâmica do COT em solos de clima tropical sob sistemas de manejo (Figura 7a). A correlação também foi observada para os compartimentos ativo $\left(R^{2}=0,84, p<0,05\right.$; Figura 7b), lento $\left(R^{2}=0,87, p<0,05\right.$; Figura 7c) e passivo $\left(R^{2}=0,91, p<0,05\right.$; Figura $\left.7 d\right)$. Os estoques de NT medidos e simulados pelo modelo Century seguiram a tendência observada nos estoques de COT e apresentaram alta correlação $\left(R^{2}=0,97\right.$, $\mathrm{p}<0,01$; Figura 7e).

\section{CONCLUSÕES}

1. Os compartimentos de $C$ ativo e lento são mais sensíveis às al terações pel o manejo do que o car bono orgânico total e o compartimento passivo. Esses compartimentos podem ser usados como indicadores da transformação da matéria orgânica do solo pelo manejo.

2. A simulação por meio do modelo Century por 120 anos indicou redução nos estoques de matéria orgânica do solo, especialmente após a mudança da Floresta Atlântica para os sistemas agrícolas convencionais. Os tratamentos com adubação orgânica recuperaram os estoques deC, especialmente no compartimento lento.

3. O modelo Century mostrou grande potencialidade para simular a dinâmica de $\mathrm{C}$ e $\mathrm{N}$ em solos de clima tropical.

\section{AGRADECIMENTOS}

À CAPES, pela bolsa de doutorado concedida ao primeiro autor. AoDr. Willian Parton ea Dr. Cindy Keough (NREL), pela colaboração nas simulações com o model o Century.

\section{LITERATURA CITADA}

BREMNER, J .M. Nitrogen total. I n: SPARKS, D.L., ed. Methods of soil analysis. Part 3. Madison, America Society of Agronomy, 1996. p.1085-1121. (SSSA Book Series:5)

CAMBARDELLA, C.A. \& ELLIOT, E.T. Particulate soil organic matter changes across a grassland cultivation sequence. Soil Sci. Soc. Am. J ., 56:777-783, 1992.

CARTER, M.R.; GREGORICH, E.G.; ANGERS, D.A.; DONALD, R.G. \& BOLINDER, M.A. Organic C and N storage and organic fractions, in adjacent cultivated and forested soils of eastern Canada. Soil Till. Res., 47:253-261, 1998. 
CHENG, H.H. \& KIMBLE, J .M. Characterization of soil organic carbon pools. In: LAL, R.; KIMBLE, J .M.; FOLLET, R.F. \& STEWART, B.A., eds. Assessment methods for soil carbon. Boca Raton, Lewis Publishers, 2001. p.117-130.

DEL GROSSO, S.J .; PARTON, W.J .; MOSIER, A.R.; HARTMAN, J .; BRENNER, D.S; OJ IMA, D.S. \& SCHIMEL, D.S. Simulated interaction of soil carbon dynamics and nitrogen trace gas fluxes using the DAYCENT model. In: SHAFFER, M.J .; MA, L. \& HANSEN, S., eds. Modeling carbon and nitrogen dynamics for soil management. Boca Raton, Lewis Publishers, 2001. p.303-332.

DUXBURY, J .M.; SMITH, M.S. \& DORAN, J.W. Soil organic matter as a source and sink of plant nutrients. In: COLEMAN, D.C.; OADES, J.M. \& UEHARA G., eds. Dynamics of soil organic matter in tropical ecosystems. Honolulu, Univesity of Hawaii, 1989. p.33-67.

FALLOON, P. \& SMITH, P. Simulating SOC changes in longterm experiments with RothC and Century: model evaluation for a regional scaleapplication. Soil Use Manag., 18:101-111, 2002.

GALVÃO, J.C.C. Características físicas e químicas do solo e produção de milho exclusivo e consorciado com feijão em função de adubações orgânica e mineral contínuas. Viçosa, UniversidadeFederal deViçosa, 1995. 194p. (TesedeDoutorado)

GALVÃO, J .C.C. E feito das adubações orgânica e mineral sobre o consórcio milho-feijão. Viçosa, Universidade Federal de Viçosa, 1988. 112p. (Tese de Mestrado)

HASSINK, J. The capacity of soils to preserve organic C and N by their association with clay and silt particles. Plant Soil, 197:77-87, 1997.

ISLAM, K.R. \& WEIL, R.R. Microwave irradiation of soil for routine measurement of microbial biomass carbon. Biol Fert. Soils, 27:408-416, 1998.

J ENKINSON, D.S. \& POWLSON, D.S. The effects of biocidal treatments on metabolism in soil. V.A. method for measuring soil biomass. Biochemistry, 8:209-213, 1976.

KELLY, R.H.; PARTON, W.J .; CROCKER, G.J .; GRACE, P.R.; KLIR, J .; KORSCHENS, M.; POULTON, P.R. \& RICHTER, D.D. Simulating trends in soil organic carbon in long-term experiments using the Century model. Geoderma, 81:7590, 1997.

LEITE, L.F.C. Compartimentos e dinâmica da matéria orgânica do sol o sob diferentes sistemas de manejo e sua simulação pel o modelo Century. Viçosa, Universidade Federal de Viçosa, 2002. 146p. (Tese de Doutorado)

LEITE, L.F.C.; MENDONÇA, E.S.; MACHADO, P.L.O.A. \& MATOS, E.S. Total $C$ and $N$ storage and organic $C$ pools of a Red-Yellow Podzolic under conventional and no tillage at the Atalantic Forest Zone, Southeastern Brazil. Austr. J. Soil Res., 41:717-730, 2003.

LIANG, B.C.; GREGORICH, E.G. \& MACKENZIE, A.F. Modeling the effects of inorganic and organic amendments on organic matter in a Quebec soil. Soil Sci., 161:109-114, 1996.

MACHADO, P.L.O.A. Fracionamento físico do sol o por densidade e granulometria para a quantificação de compartimentos da matéria orgânica do solo - um procedimento para a estimativa pormenorizada do seqüestro de carbono pel o solo. Rio de J aneiro, EMBRAPA Solos, 2002. 6p. (Comunicado Técnico, 9)
MOTAVALLI, P.P.; PALM, P.C.A.; PARTON, W.J .; ELLIOT, E.T. \& FREYS, S.D. Comparison of laboratory and modeling simulation methods for estimating soil carbon pools in tropical forest soils. Soil Biol. Biochem., 26:935-944, 1994.

PALM, C.A.; GACHENGO, C.N.; DELVE, R.J .; CADISCH, G. \& GILLER, K.E. Organic inputs for soil fertility management in tropical agroecosystems: application of an organic resource database. Agric. E cosys. Environ., 83:27-42, 2001.

PARTON, W.J .; SCHIMEL, D.S.; COLE, C.V. \& OJIMA, D.S. Analysis of factors controlling soil organic matter levels in great plains grasslands. Soil Sci. Soc. Am.J ., 51:1173-1179, 1987.

PARTON, W.J .; STEWART, J .W.B. \& COLE, C.V. Dynamics of C, N, P eS in grassland soils: A Model. Biogeochem., 5:109131, 1988.

PAUL, E.A. Dynamics of organic matter in soils. Plant Soil, 76:275-285, 1984.

PAUSTIAN, R.; PARTON, W.J . \& PERSSON, J . Modeling soil organic matter in organic-amended and nitrogen-fertilized long-term plots. Soil Sci. Soc. Am. J ., 56:476-488, 1992.

PING, C.L.; MICHAELSON, G.L.; DAI, X.Y. \& CANDLER, R.J . Characterization of soil organic matter. In: $L A L, R$.; KIMBLE, J .M.; FOLLETT, R.F. \& STEWART, B.A., eds. Assessment methods of soil carbon. Boca Raton, CRC Press, 2001. p.273-284.

POWLSON, D.S.; BROOKES, P.C. \& CHRISTENSEN, B.T. Measurement of soil microbial biomass provides an early indication of changes in total soil organic matter due to straw incorporation. Soil Biol. Biochem., 19:159-164, 1987.

REICOSKY, D.C.; KEMPER, W.D.; LANGDALE, G.W.; DOUGLAS J r., C.L. \& RASMUSSEN, P.E. Soil organic matter changes resulting from tillage and biomass production. Soil Water Conserv. J ., 50:253-261.

SHAFFER, M.J.; MA, L. \& HANSEN, S. Introduction to simulation of carbon and nitrogen dynamics in soils In: SHAFFER, M.J .; MA, L. \& HANSEN, S., eds. Modeling carbon and nitrogen dynamics for soil management. Boca Raton, Lewis Publishers, 2001. p11-26.

SOHI, S.; MAHIEU, N.; ARAH, J.R.M.; POLWSON, D.S.P.; MADARI, B. \& GAUNT, J .L. A procedure for isolating soil organic matter fractions suitable for modeling. Soil Sci. Soc. Am. J ., 65:1121-1128, 2001.

SPARLING, G.P. \& WEST, A.W. A direct extraction method to estimate soil microbial C:calibration in situ using microbial respiration and ${ }^{14} \mathrm{C}$ labelled cells. Soil Biol. Biochem., 20:337-343, 1988.

VARADACHARI, C.; MONDAL, A.H.; NAYAK, D.C. \& GHOSH, $\mathrm{K}$. Clay-humus complexation: effect of $\mathrm{pH}$ and the nature of bonding. Soil Biol. Biochem., 26:1145-1149. 1994.

WATSON, R.T.; NOBLE, I.R.; BOLIN B.; RAVINDRANATH, N.H.; VERARDO, D.J . \& DOKKEN, D.J . Land use, land use change and forestry: a special report of the IPCC. Cambridge: Cambridge, University Press, 2000. 377p.

WOOMER P.L.; MARTIM, A.; ALBRECHT, A.; RESCK, D.V.S. $\&$ SCHARPENSEEL, H.W. The importance and management of soil organic matter in the tropics. In: WOOMER, P.L. \& SWIFT, M.J ., eds. The biological management of tropical soil fertility. Chichester, J ohn Wiley \& Sons, 1994. p.47-80.

YEOMANS, J.C.\& BREMNER,J.M. A rapid and precise method for routine determination of organic carbon in soil. Comm. Soil Sci. Plant Anal., 19:1467-1476, 1988. 